Kennesaw State University

DigitalCommons@Kennesaw State University

Faculty Publications

Spring 4-7-2020

\title{
The expanded view of individualism and collectivism: One, two, or four dimensions?
}

\author{
Jennifer L. Priestley \\ Kennesaw State University, jpriestl@kennesaw.edu \\ Kamal Fatehi \\ Kennesaw State University \\ Gita Taasoobshirazi \\ Kennesaw State University
}

Follow this and additional works at: https://digitalcommons.kennesaw.edu/facpubs

Part of the International Business Commons, Marketing Commons, and the Multivariate Analysis Commons

\section{Recommended Citation}

Fatehi, K., Priestley, J. L., \& Taasoobshirazi, G. (2020). The expanded view of individualism and collectivism: One, two, or four dimensions? International Journal of Cross Cultural Management, 20(1), 7-24.

This Article is brought to you for free and open access by DigitalCommons@Kennesaw State University. It has been accepted for inclusion in Faculty Publications by an authorized administrator of DigitalCommons@Kennesaw State University. For more information, please contact digitalcommons@kennesaw.edu. 


\title{
The expanded view of individualism and collectivism: One, two, or four dimensions?
}

International Journal of Cross Cultural Management 2020, Vol. 20(I) 7-24 (c) The Author(s) 2020 Article reuse guidelines: sagepub.com/journals-permissions DOI: 10.1/77/14705958209/3077 journals.sagepub.com/home/ccm

(S)SAGE

\author{
Kamal Fatehi ${ }^{\circledR}$, Jennifer L Priestley \\ and Gita Taasoobshirazi \\ Kennesaw State University, USA
}

\begin{abstract}
Recent research to analyze and discuss cultural differences has employed a combination of five major dimensions of individualism-collectivism, power distance, uncertainty avoidance, femininitymasculinity (gender role differentiation), and long-term orientation. Among these dimensions, individualism-collectivism has received the most attention. Chronologically, this cultural attribute has been regarded as one, then two, and more recently, four dimensions of horizontal and vertical individualism and collectivism. However, research on this issue has not been conclusive and some have argued against this expansion. The current study attempts to explain and clarify this discussion by using a shortened version of the scale developed by Singelis et al. ((1995) Horizontal and vertical dimensions of individualism and collectivism: a theoretical and measurement refinement. CrossCultural Research 29(3): 240-275). Our analysis of aggregate data from 802 respondents from nine countries supports the expanded view. Data aggregation was based on the Mindscape Theory that proposes inter- and intracultural heterogeneity. This finding is reassuring to scholars who have been using the shortened version of the instrument because confirmatory factor analysis indicated its validity. The findings of the present study provides clarification of some apparent ambiguity in recent research in specifying some cultures such as India, Israel, and Spain as individualists or collectivists. By separating the four constructs, more nuanced classification is possible. Also, such a distinction enables us to entertain such concepts as the Mindscape Theory that proposes a unique intracultural and transcultural heterogeneity that do not stereotype the whole culture as either individualist or collectivist.
\end{abstract}

\section{Keywords}

Cultural dimensions, cultural metaphors, individualism and collectivism, Mindscape Theory

\section{Corresponding author:}

Kamal Fatehi, School of Management, Entrepreneurship and Hospitality, Coles College of Business, Kennesaw State University, 560 Parliament Garden Way, Kennesaw, GA 30144-8599, USA.

Email: kfatehi@kennesaw.edu 


\section{Introduction}

Culture is a very complex construct. It has been studied in many fields, including anthropology, psychology, sociology, and management. Each of these fields has used its own methodology and terminology, which makes an already complex construct much more difficult even to specialists. Despite its complexity or possibly because of it, often, it has been defined and operationalized simplistically (Taras et al., 2009: 358). We could study culture in two major approaches, etic or emic (Gannon, 2009). The etic approach enables researchers to compare cultures. Hofstede (2001), House et al. (2004) and their followers have used etic or cultural-general approaches. This line of research has dominated the field of cultural studies. The emic method or culture-specific (e.g. Gannon, 2004, 2009; Gannon and Pillai, 2009; Montague and Morais, 1975; Nielsen and Mariotto, 2005/2006) has received less attention.

While the influence of Hofstede's research undeniably is immense, its limitations should not be overlooked. The aim of this article is not a critique of Hofstede's work. Others have elaborated on this issue extensively (e.g. Gannon, 2009; McSweeney, 2002a, 2002b, 2013; Sivakumar and Nakada, 2001; Tung, 2008). However, it will be remiss not to mention that its focus has been on values to the exclusion of practices. Also, there have been inconsistencies in his presentation. For example, in his 1980 book, among 53 national cultures, Japan was ranked 22/23 on the individualism-collectivism dimension thus placing it on an individualistic category. In his second edition of the book, Japan was considered moderately collectivistic. Which one is it? The limitation of using only value scales has been addressed by the GLOBE study that added nine practice scales. Other alternatives have been suggested by Gannon (2008), Gannon and Audia (2000), Gannon et al. (2005/2006), and Gannon and Pillai (2009). Also, some other issues were raised by researchers regarding the Hofstede's works. There is often a dichotomy between values and practices in most cultures. The GLOBE study, however, revealed that the most significant difference between values and practices in the Hofstede study was in the area of the "Power Distance" dimension, an essential factor in any cross-cultural research.

The etic approach to study culture is more popular than the emic approach. This preference could be due to the difference between quantitative and qualitative methods that are employed by both approaches, respectively. The application of cultural dimensions of the etic approach lends itself to quantification. Quantification of any construct in a research project makes comparison with other constructs easier and, therefore, more popular. A few scholars such as Gannon (2004, 2008, 2011, 2012) and Gannon and Pillai $(2009,2016)$ have offered a rich vein of inquiry with the use of "metaphors" to study cultures.

The application of metaphors, so far, has been a qualitative method that is not as easy to use as the quantitative ways of cultural dimensions. Of course, marrying both quantitative and qualitative approaches is the best option. At present, this option is not available. However, Gannon and Deb (2018: 318), by the inclusion of the "paradox" construct, have suggested the two can form a complementary feedback loop. "Thus, the initial understanding of cross-cultural behavior that is obtained through the dimensional approach, and deepened through the use of the cultural metaphoric approach, is enriched by incorporating the paradoxical approach. The resultant feedback loops capture the dynamic interactions among these three approaches." At present, however, most of cross-cultural inquiries and discussions apply various forms of cultural dimensions. In this article, we examine one such study.

The study of cultures is the study of differences and variations. In turn, as we mentioned earlier, the discussion of cultural differences is commonly and inexorably linked with the application of 
cultural dimensions (e.g. Hofstede, 1980, 2001). Over the years, scholars have identified and discussed many cultural dimensions (e.g. Douglas, 1970, 1982; Klukhohn and Strodtbeck, 1961; Kuhn and McParland, 1954; Parsons and Shills, 1951; Thompson and Wildavsky, 1986). Osland and Bird (2000) listed 22 of these cultural dimensions. The application of cultural dimensions enables researchers to compare cultures on various factors. Most studies, however, have examined four major cultural dimensions, including individualism-collectivism, power distance, uncertainty avoidance, and gender role differentiation or femininity-masculinity that were popularized by Hofstede (1980). Later, Hofstede and Bond (1988) expanded these dimensions to five. The GLOBE project (House et al., 1999, 2004) further expanded these dimensions to nine. Specifically, House et al. (1999) considered collectivism as either institutional or in-group. Others have offered yet different ways of distinguishing cultural features (e.g. Trompenaars and HampdenTurner, 1998). Individualism and collectivism (IND-COL) have been studied more extensively than other cultural dimensions. Some have argued that the concepts of IND-COL are more complex and suggested expanding them further. The pioneers of this line of inquiry are Singelis et al. (1995), and Triandis and Gelfand (1998) whose works have been the basis of many studies dealing with various subjects.

In the present study, we attempt to corroborate Singelis et al.'s (1995) positions and carry out the recommendation of Sivadas et al. (2008: 209), who inconclusively researched the relevance of the proposed dimension. They suggested that future research examining the dimensions of IND-COL should be conducted with a larger multi-country sample. Therefore, the current study adopts the original scale by Singelis et al. (1995), albeit an abridged version that was utilized by Triandis and Gelfand (1998). Below, we explain the adoption of this shorter version. In so doing, data from 802 respondents in nine countries were collected and pooled together and analyzed. The nine-country study and a large number of participants in the survey provide the data necessary for assessing the construct validity of the instrument using confirmatory factor analysis. Although we enlisted the cooperation of friends and colleagues for data collection in 11 countries, the final sample for data analysis included only nine countries.

Several researchers had studied measurement equivalence and invariance of the items across countries, men, and women, and even between ethnic groups in the United States (e.g. Chiou, 2001; Guo et al., 2008). For various reasons, including low factor loading, researchers had to exclude some of the 32 items for their analysis. Others who had applied this scale in a few countries, for example, Chiou (2001) in the United States, Taiwan, and Argentina or Sivada et al. (2008) in China, Denmark, India, and the United States, and in a single country, that is, Singapore (Soh and Leong, 2002), had more evidence for measurement equivalence than invariance with findings for measurement invariance being minor. Additionally, when Sivadas et al. (2008) had to reduce the original 32-item scale to a 14-item scale, due to the low factor loading of some items, this shorter scale had only five items overlapping with the one applied by Triandis and Gelfand (1998). Similarly, Triandis and Gelfand (1998) had excluded from their study some items. Such a variation prompted us to combine the data from all countries for our analysis. Notwithstanding this issue, the Mindscape Theory [explained later] offers a substantive explanation for data pooling.

Regardless of the theoretical position of one, two, or four-dimensionality of the cultural attributes of IND-COL, these attributes are pertinent to all cultures. However, the frequency for each of the HVIC dimensions varies across countries. Singelis et al. (1995) did not propose these dimensions to be the exclusive domain of a particular country/culture. The relevance of these dimensions to all cultures prompted our combined nine-country data analysis. Additionally, the Mindscape Theory provides more justification for the pooling of the nine-country data. 
This article is organized in the following order. First, Mindscape Theory is discussed. This discussion provides an additional explanation for a specific aspect of the methodology, namely the pooling of the nine-country data for analysis. Then we offer background literature on the dimensionality of the constructs under investigation. In part three, we explain the methodology and data analysis. The article ends up with a conclusion and elaborates on the findings.

\section{Mindscape Theory}

Mindscape Theory proposes that various types of personality characteristics (Mindscape types) are present in all cultures, and these are not the exclusive domain of a particular culture. Cultural differences (national stereotypes) are due to the case that one type becomes dominant and marginalizes all other types.

The issue of cultural heterogeneity has been theoretically advocated (e.g. Venaik and Midgley, 2015) and empirically tested (e.g. Fatehi and Priestley, 2018; Fatehi et al., 2015, 2018). This position not only is a realistic one, and intuitively appealing, but research by many scholars suggested intracultural heterogeneity ( e.g. Au, 1999, 2000; Au and Cheung, 2004; Brewer and Venaik, 2012; Gurven et al., 2008; Kirkman et al., 2006; McSweeney, 2002a, 2002b, 2013; Tung, 2008), and both, inter- and intracultural heterogeneity (e.g. Fatehi and Priestley, 2018, Fatehi et al. 2015, 2018; and Maruyama's extensive writings on the Mindscape Theory, 1980-2004). In all cultures, some individuals have similarities in logic, values, beliefs, and behavior with some people of their own and or other cultures. Support for the Mindscape Theory is provided by many researchers including Dockens (2009), Fatehi and Priestley (2018), and Fatehi et al. (2015, 2018), Gammack (2002), Hatt (2009), Hentschel and Sumbadze (2002), and Yolles and Fink (2009).

Inkeles and Levinson (1969 [1954]: 424), who established the theoretical foundation upon which rests the proposed cultural dimensions of Hofstede (Minkov and Hofstede, 2011: 12), asserted that “.... there are actually a great variety of individual personality characteristics and patternings [sic] in any society; a modal personality structure is, then, one that appears with considerable frequency There may, of course, be several modes in any distribution of variants."

According to the Mindscape Theory, the heterogeneity of values, logic, and mentality exist among individuals in all cultures. For various reasons, some types, however, become dominant and extend their control and influence over other types. The nondominant types find it necessary to accept domination. Personal benefits, convenience, and expedience compel the nondominant type individuals to transform, hide, or camouflage their true types in favor of the dominant type. To survive and to fit into the society, they develop various strategies that could include avoiding the mainstream dominant type, finding a niche, disguising one's type, and switching back and forth in private and public life. Some cases are reversible repressions, reformers, rebels, or troublemakers. Some other cases are drop-outs or emigrants (e.g. Maruyama, 1992a, 1992b, 1994, 1995, 1999).

Consequently, the acceptance of this dominance by the nondominant types and the various tactics such as suppressing, transforming, or ignoring other kinds that are used by the dominant types give the appearance of homogeneity in cultures.

\section{Background literature and dimensionality}

Considerable research in organizational studies has followed the footsteps of Hofstede (1980), who popularized four and then five major cultural dimensions. Among these cultural dimensions, INDCOL have received the most attention (Kirkmann et al., 2006; Tsui et al., 2007). IND-COL 
distinction are based on the concept of self-construal that considers the degree of fundamental relatedness of individuals to one another (Markus and Kitayama, 1991, 2003; Triandis, 1995).

Self-construal varies among cultures. Individuals are socialized to conform to the prevailing concept of self-construal. In some cultures, individuals are considered independent and separate psychologically from other individuals. In other cultures, individuals are regarded as interdependent and continually aware of the situational context of which they are a part of the larger entity of a collective. In individualistic cultures, people behave according to self-interest and personal preferences and consider independence and self-sufficiency very important. In collectivist cultures, groups are of primary importance-individuals are secondary. In these cultures, individuals acknowledge the contributions of others to their existence. They may sacrifice self-interest to promote the interest of the collective.

Based on the writings of Triandis (1993), Bobbio and Sarrica (2009: 210), who conducted their study in Italy, suggested that four attributes could differentiate individualistic and collectivist cultures: (a) independent or interdependent self-construal; (b) degree of importance given to personal or group goals; (c) priority of individual attitudes or social norms in guiding behaviors; [and] (d) focus on exchange relationships or communal relationships. Cultures that are considered individualistic include the United States, Australia, and most Western countries. Most Asian countries, such as China, Japan, and Korea, are considered collectivists.

Besides from being studied extensively - which signifies their importance-IND-COL appears to be more problematic to research (Carnevale and Leung, 2001; Green et al., 2005) than initially assumed. Some have questioned whether IND-COL forms the opposite ends of a single continuum or form two independent constructs. Also, they have challenged the validity of IND-COL due to its ambiguity of the boundaries and scope (Kim et al., 1995; Levine et al., 2007; Voronov and Singer, 2002).

As proposed by Hofstede (1980) [in his national dimensions studies], individualism was considered the opposite of collectivism, meaning that the two were at the ends of the same continuum (Oyserman et al., 2002; Taras et al., 2013), implying uni-dimensionality. A different position was advocated by Markus and Kitayama (1991), Osyerman (1993), and Singelis (1994). They suggested that both IND-COL are separate dimensions, implying bi-dimensionality. As Singelis (1994: 588) asserted, "... when the unit of analysis is the individual... one must consider these dimensions separately." Furthermore, in a refinement of this position, Singelis et al. (1995) and Triandis and Gelfand (1998) proposed that each of these dimensions consists of two separate forms - horizontal or vertical-implying quadra-dimensionality. They distinguished between vertical and horizontal IND-COL (i.e. VI, HI, VC, HC) by the application of concepts of independent and interdependent self (Markus and Kitayama, 1991, 2003; Triandis, 1995). Attributes of these dimensions are depicted in Table 1. American (the United States) and many Western cultures view "self" as independent and separate from others. This position leads to attending to goals, wishes, and desires of "self," with such common sayings as 'self-expression,' 'self-fulfillment,' 'self-actualization,' and so forth. Most Asians, on the other hand, insist on the interdependence of individuals, which leads to 'fitting in' and keeping the intragroup 'harmony.' In this regard, a common Japanese saying is relevant: A nail that stands out is hammered down!

The horizontal view of IND-COL emphasizes equality among members where egalitarian norms are observed. The vertical view emphasizes the acceptance of hierarchy, where status and achievement is essential. As an example, Singelis et al. (1995: 246), suggested that “ . . extreme HC is the pattern of pure communism, whereas moderate $\mathrm{HC}$ is the pattern found in the Israeli Kibbutz. Extreme VC is the case of Nazi Germany, whereas moderate VC can be found in most traditional 
Table I. Attributes of cultural orientation of horizontal and vertical individualism and collectivism.

\begin{tabular}{lll}
\hline \multirow{2}{*}{$\begin{array}{l}\text { Cultural } \\
\text { orientation }\end{array}$} & Dimension (hierarchy) \\
\cline { 2 - 3 } Individualism & $\begin{array}{c}\text { Herizontal } \\
\text { Independent/autonomous self and } \\
\text { similar to others, equality in } \\
\text { status. }\end{array}$ & $\begin{array}{c}\text { Independent/autonomous self and different from others, } \\
\text { status differential expected and accepted } \rightarrow \\
\text { inequality, intragroup competition, submission to } \\
\text { authority. }\end{array}$ \\
& $\begin{array}{c}\text { Interdependent self and similar to } \\
\text { others, equality in status. }\end{array}$ & $\begin{array}{c}\text { Interdependent self and different than others, status } \\
\text { differential } \rightarrow \text { inequality is accepted, self-sacrifice for } \\
\text { in-group is essential, submission to authority. }\end{array}$ \\
\hline
\end{tabular}

Greek villages ... individuals could exhibit each of these patterns at different times or in different situations." According to Triandis (1995), the United States and France are examples of VI, while Sweden and Australia are examples of HI.

The four dimensions of HI, HC, VI, and VC are very much similar to what Fiske (1992) identified as four patterns for resource distribution in all cultures: communal sharing (HC), authority ranking (VC), equality matching (HI), and market pricing (VI). In authority ranking, there is a linear ordering of positions with related benefits. In the case of equality matching, equality is the rule, and all share similarly. In communal sharing, each member of the group receives a share based on personal needs. Market pricing is the distribution of resources based on the person's contributions. Figure 1 depicts a combination of V-H, I-C and Fiske's pattern of resource distribution in societies.

Singelis et al. (1995) developed a scale to test the proposed quadra-dimensionality of individualism-collectivism empirically. The new scale that measured social relationships at the individual level of analysis was adopted by many researchers and resulted in scholarly publications across a wide range of topics. Some, for example, used the scale for comparing various psychological and social constructs among the United States people and other countries (e.g. Chiou, 2001; Cukur et al., 2004; Gouveia et al., 2003; Karramaju et al., 2008; Komarraju and Cokley, 2008; Nelson and Shavitt, 2002). These studies indicated the new scale is useful in differentiating value preferences in various cultural settings. Others used this new scale to explain cultural orientation among different ethnic groups in the United States (Oyserman et al., 2002; Vargas and Kemmelmeier, 2013). Abraham (1997) examined the relationship between horizontal and vertical IND-COL with organizational commitment. It was found that horizontal individualism could explain intrapreneurship, and vertical collectivism and organizational commitment have a positive relationship. Chirkov et al. (2005) described horizontal and vertical IND-COL ties with cultural distance. Lee and Choi (2005) investigated the role of horizontal and vertical IND-COL on persuasive communication on the Web. Their findings suggested that the new scale was more robust in explaining the perceived Web skills than the traditional dichotomous continuum of IND-COL. Komarraju et al. (2008) studied the differences in conflict management styles among people with horizontal and vertical IND-COL orientation. In their study, among other findings, it was noted that people with horizontal and vertical collectivism orientations have a different preference for conflict management styles.

Noordin et al. (2002) examined the differences between career commitment of Australian and Malaysian managers using the new scale. Their findings indicated no difference between Australian and Malaysian managers in career planning and career identity commitment. Le (2005) related ludus 


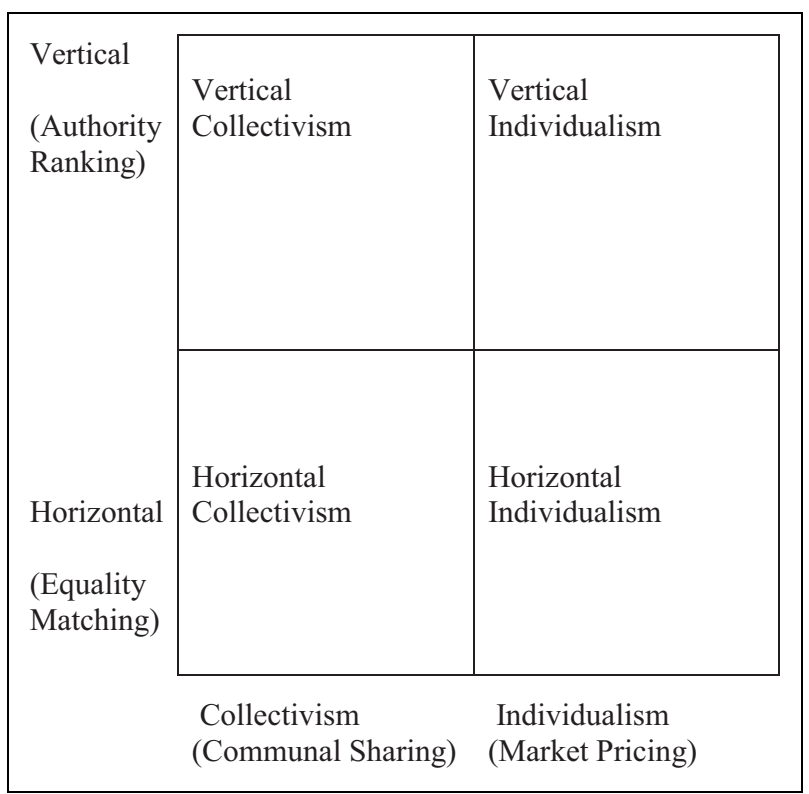

Figure I. Resource sharing pattern and horizontal and vertical individualism and collectivism.

and narcissism to the four constructs of HI, VI, HC, and VC. Le (2005) found a positive relationship between vertical individualism and ludus, a game-playing love style. The results of a study by Hornik and Tupchiy (2006) indicated that the four dimensions of HI, VI, HC, and VC have a different effect on the application of technology-mediated learning. Findings of an online survey by Lee and Choi (2005) suggested that the four cultural dimensions of IND-COL have a different effect on the orientation of Web users toward Web advertising and perceived Web skills. Györkös and colleagues (2012) studied the Singelis et al.'s scale by analyzing data collected in Switzerland $(N=$ $585)$ and South Africa $(N=1404)$ and compared it with Auckland Individualism and Collectivism Scale. They found cross-cultural replicability of both instruments.

In short, the scale started a variety of scholarly inquiries similar to the proliferation of research studies after the application of the cultural dimensions by Hofstede in the 1980s. The expanded view of cultural dimensions of IND-COL, however, was not fully supported by some research studies conducted in other countries. A survey by Gouveia et al. (2003) examined the factorial structure and the dimensionality of the scale by analyzing data from 526 Spanish responses to the 32-item scale. While they found evidence of four factors, the overall fit of the data to a confirmatory factor analysis model was moderate. Additionally, the study had difficulty in distinguishing between the collectivism sub-dimensions. In a study with Italian subjects $(N=308)$, Bobbio and Sarrica (2009) used the 32 items of the scale by Singelis et al. (1995). They examined the relationship between IND-COL aspects, conflict management, and leadership style. They found only three factors, horizontal and vertical individualism (HI, VI) and a single general dimension of collectivism (C).

As researchers encountered some problems with the original 32-item scale, they began excluding some of the items from their analyses. For example, Probst (1999) retained only 21 of the 32 questions. Kurman and Siraram (2002) used only 20 questions, and Soh and Leong (2002) applied 16 items from the 32-item scale. Cukur et al. (2004) kept only 16 of the 32 items. Triandis 
and Gelfand (1988) in the process of improving the Singelis et al.'s (1995) instrument found that the 16 items of the same scale exhibited higher factor loadings. Since then, researchers tended to use the more parsimonious 16-item scale of the 32-item. We used the same 16-item scale but substituted one item with another item of the same scale. The purpose of this modification was to make it easier for non-English speaking subjects to comprehend the scale. This modification is explained shortly.

In the present study, we examine the psychometric properties of the Singelis et al. (1995) scale as revised by Triandis and Gelfand (1998) by examining the 16-item scale with a large multi-country sample as recommended by Sivades et al. (2008). We assessed the psychometric properties of the 16-item instrument by using confirmatory factor analysis and data from nine different countries. Specifically, using a large and multicultural sample, we discuss whether IND-COL are better perceived as having two, three, or four dimensions. Also, we compared two, three, and four-factor nested models of the hypothesized constructs. The examination of the psychometric properties of the 16 item instrument is essential given that a different number of constructs (two, three, and four) and variations in the items of the survey have been used in the research. For example, Singelis et al. (1995) presented 32 items; Triandis and Gelfand (1998) used 27 questions which were cut down by other researchers to 16 items or less.

\section{Methodology}

This study aimed to examine the proposed quadra-dimensionality of cultural dimensions of INDCOL and not cultural differences in these factors. Therefore, the sample size for each country is not pertinent, but rather the total combined sample is relevant. Additionally, in a situation as this, data aggregation is supported by the Mindscape Theory, too, that suggests intercultural and intracultural heterogeneity (e.g. Dockens, 2009; Fatehi et al., 2015; Gammack, 2002; Hatt, 2009; Hentschel and Sumbadze, 2002; Maruyama, 1980, 1992a, 1992b, 1994, 1995, 1999, 2004; Yolles and Fink, 2009). The Mindscape Theory proposes that there are individuals in each culture, who have similarities with some people in their own or other cultures. Mindscape Theory was presented earlier.

\section{The instrument and the subjects}

In this study, we used the 16-item version of the Singelis et al. (1995) scale (see Appendix 1). This version was initially devised by Triandis and Gelfand (1998). The questionnaire was in English. All respondents were proficient in English either as the university students who enrolled in programs where the medium of teaching was the English language or were office workers where they regularly used the English language in their daily work. We divided the 16 items evenly between the four constructs of $\mathrm{HC}, \mathrm{VC}, \mathrm{HI}$, and VI. In the present study, we made a slight change. Item number 2 of Triandis and Gelfand (1998) was replaced with item number 13 (an item on the original 32 items of Singelis et al., 1995) which reads, "I prefer to be direct and forthright when discussing with people." We thought that the people of other cultures might not fully comprehend item \#2, which reads, "I often do "my own thing." The selection of item \#13 was also aided by the fact that it had a similar high factor loading and was in the same category as item \#2 that it replaced. These 16 items were randomized to create our survey.

The convenience sample of 802 subjects included 176 managers and office workers, and 626 undergraduate students in nine countries. According to Smith and Schwartz (1997), teachers and students are the best populations for analyzing cultural values. Students' age varied from 17 to 35 . This wide-range age distribution extirpates concern for the uniformity in the age which often is the 
Table 2. Demographic distribution by age and gender.

\begin{tabular}{lrrrrrrrrr}
\hline Countries & $17-24$ & $25-29$ & $30-34$ & $>35$ & Age missing & Male & Female & Gender missing & Total \\
\hline Belgium & 58 & 24 & 4 & 2 & 1 & 42 & 47 & 0 & 89 \\
Iran & 35 & 24 & 9 & 8 & 1 & 26 & 50 & 1 & 77 \\
Jordan & 45 & 23 & 5 & 4 & 1 & 22 & 56 & 0 & 78 \\
Kazakhstan & 30 & 0 & 0 & 0 & 0 & 17 & 13 & 0 & 30 \\
Mexico & 89 & 0 & 0 & 0 & 1 & 53 & 36 & 1 & 90 \\
New Zealand & 18 & 9 & 3 & 3 & 2 & 14 & 21 & 0 & 35 \\
Romania & 0 & 2 & 6 & 27 & 2 & 11 & 25 & 1 & 37 \\
USA & 214 & 37 & 10 & 52 & 13 & 145 & 174 & 7 & 326 \\
Vietnam & 21 & 15 & 3 & 1 & 0 & 17 & 23 & 0 & 40 \\
Total & 510 & 134 & 40 & 97 & 21 & 347 & 445 & 10 & 802 \\
\hline
\end{tabular}

case in student samples. There were 360 males, 457 females, and 10 missing data on gender. Table 2 contains descriptive statistics of the sample.

Since the main point of this study was the clarification of the proposed quadra-dimensionality of individualism-collectivism, as suggested by Singelis et al. (1995), the combined data were analyzed and discussed. Earlier in the article, we presented the explanation for data pooling.

\section{Data analysis}

Confirmatory factor analysis. Three nested models were tested to the data using confirmatory factor analysis. Because the data met the assumptions of both univariate and multivariate normality, the data were analyzed using the maximum likelihood estimation technique. The data were analyzed using LISREL and PRELIS. After using listwise deletion, the final sample size was $n=777$, with only 25 missing completely at random data observations. The first model was a two factor model with two constructs: individualism ( 8 individualism items) and collectivism ( 8 collectivism items). The fit of the model was acceptable as indicated by: $\chi^{2}$ with 103 degrees of freedom $=773.650(p=$ $0.0000)$, $\mathrm{RMSEA}=0.09, \mathrm{SRMR}=0.07, \mathrm{GFI}=0.87$.

The second model was a four-factor model with four constructs: horizontal individualism, horizontal collectivism, vertical individualism, and vertical collectivism. The fit of the model was good and improved from the two factor model as indicated by a $\chi^{2}$ with 98 degrees of freedom $=$ 640.272 $(p=0.0000), \mathrm{RMSEA}=0.08, \mathrm{SRMR}=0.07, \mathrm{GFI}=0.90 . \mathrm{A} \chi^{2}$ difference test with $d f=5$, $\chi^{2}=133.378$, and critical value of 11.1 indicated that the four-factor model had a better fit. A model with two factors of all horizontal and all vertical items were also tested and found to be of inferior fit to the four-factor model.

Bobbio and Sarrica (2009) who examined the relationship between IND-COL aspects, conflict management, and leadership style found only three factors when examining the dimensions of the scale, including horizontal and vertical individualism (HI, VI) and a single general dimension of collectivism (C). Thus, in the present study, a model with these three constructs was tested and had the following fit index values: $\chi^{2}$ with 101 degrees of freedom $=690.105(p=0.0000)$, RMSEA $=$ $0.09, \mathrm{SRMR}=0.07, \mathrm{GFI}=.89$. Although the fit of this three-factor model was better than the two-factor model as indicated by a $\chi^{2}$ difference test $\left(\chi^{2}\right.$ difference test value with 2 degrees of freedom $=83.55)$, the four-factor model was the best fit model even when compared to the threefactor model $\left(\chi^{2}\right.$ difference test value with three degrees of freedom $\left.=49.83\right)$. The four-factor 


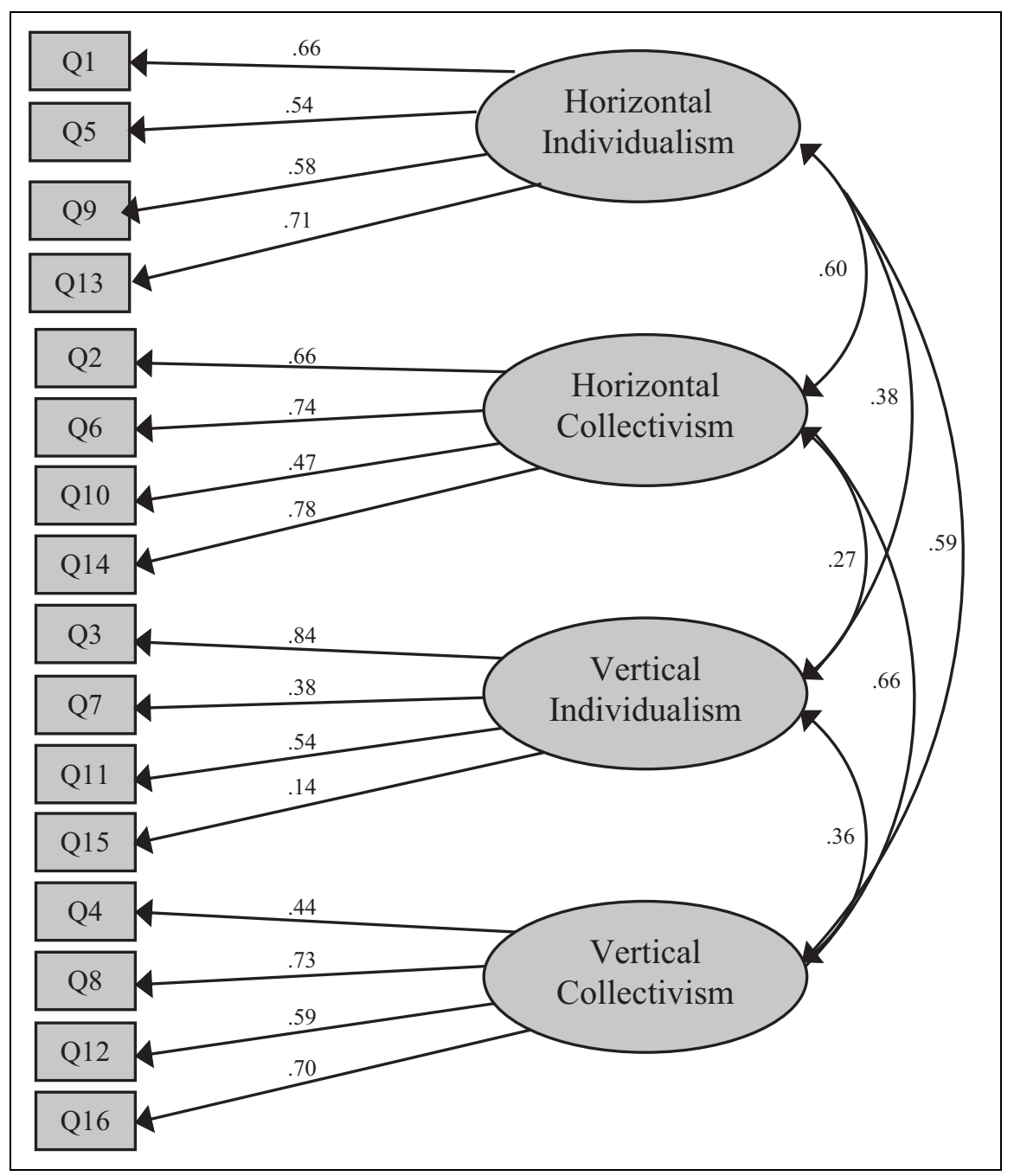

Figure 2. Confirmatory factor analysis model.

model, which did the best job in representing the dimensions of the 16 items, with standardized factor loadings, are presented in Figure 2. All loadings were significant at $p=0.05$. In Table 3, we present the items and factor loadings as well as Cronbach's $\alpha$ and variance explained in the items by the factors.

\section{Discussion and conclusion}

Our analysis of a large dataset from nine countries/cultures supports the position espoused by Singelis et al. (1995) of four constructs of HI, HC, VI, and VC. Furthermore, it supported the fourfactor structure using only 16 of the 32 items of the Singelis scale. This finding is reassuring given that researchers have been using the shortened version of the instrument even though the structure of 
Table 3. Item loadings.

Item \# Item loading ( $t$ value)

Factor I. Horizontal individualism (Cronbach $\alpha=0.67$ )

I $\quad 0.69(20.35)$ l'd rather depend on myself than others. $R^{2}=0.47$.

$5 \quad 0.53$ (14.88) I rely on myself most of the time; I rarely rely on others. $R^{2}=0.28$.

90.59 (I6.8I) My personal identity, independent of others, is very important to me. $R^{2}=0.34$.

I3 $0.72(21.59)$ I prefer to be direct and forthright when discussing with people. $R^{2}=0.5$ I

Factor 2. Horizontal collectivism (Cronbach $\alpha=0.76$ )

20.63 (18.69) If a coworker gets a prize, I would feel proud. $R^{2}=0.40$.

$6 \quad 0.75$ (23.34) The well-being of my coworkers is important to me. $R^{2}=0.56$.

$100.50(14.1 \mathrm{I})$ To me, pleasure is spending time with others. $R^{2}=0.25$.

I4 $0.80(25.32)$ I feel good when I cooperate with others. $R^{2}=0.64$.

Factor 3. Vertical individualism (Cronbach $\alpha=0.58$ )

$3 \quad 0.84(22.56)$ It is important that I do my job better than others. $R^{2}=0.70$.

$7 \quad 0.32(8.34) \quad$ Winning is everything. $R^{2}=0.10$.

II 0.54 (14.62) Competition is the law of nature. $R^{2}=0.29$.

$150.12(2.91)$ When another person does better than I do, I get tense. $R^{2}=0.01$.

Factor 4. Vertical collectivism (Cronbach $\alpha=0.7 \mathrm{I}$ )

$4 \quad 0.39$ (10.83) Parents and children must stay together as much as possible. $R^{2}=0.16$.

$8 \quad 0.72(21.95)$ It is my duty to take care of my family even when I have to sacrifice what I want. $R^{2}=0.52$

I2 0.57 (16.28) Family members should stick together no matter what sacrifices are required. $R^{2}=0.32$.

I6 $0.73(22.15)$ It is important to me that I respect the decisions made by my groups. $R^{2}=0.53$.

Note: On the far left are item numbers followed by factor loadings. $t$ Values are in parentheses.

the shortened instrument had not been validated using confirmatory factor analysis. Using instruments that have established evidence of validity and reliability is critical and can be crucial to the findings and implications of a study.

The distinction between four constructs is useful in sorting out some apparent difficulty in specifying some cultures as individualist or collectivist. It is impossible to determine if some cultures, for example, as India, Israel, and Spain are collectivist or individualist. This problem could be due to, among other factors, the fact that by combining vertical and horizontal components of these dimensions, we confound the issue further. By separating the four constructs, more classification is possible. Also, such a distinction enables us to entertain such concepts as the Mindscape Theory (e.g. Maruyama, 1980) that proposes a unique intracultural and transcultural heterogeneity that do not stereotype the whole culture as either individualist or collectivist.

We want to point out that coefficient $\alpha$ reliability values are below the recommended 0.70 for the individualism related components in our study. This finding is consistent with the range of coefficient $\alpha$ s found for the four components in the Singles et al. (1995) study ( $\alpha$ ranges from 0.67 to 0.74). Some revisions to the instrument may be helpful to increase the internal consistency of the scale. The revised items could measure more current aspects of individuals' HI, VI, VC, and HC beliefs related to the use of technology and social media. Such a revision can help update the issues assessed by the instrument in the 25 years since it was developed. Of course, refining the inventory by substituting/adding items could improve its reliability, 
We believe that the instrument can be used with numerous cultural, work-related, demographic, and educational, psychological, and social outcome variables to understand how these variables interact. For example, a structural equation, multilevel, or regression model can be used to determine how cultural, work-related issues such as superior-subordinate relationship, demographic, educational, psychological, and social outcome variables impact responses on the scale developed by Singelis et al. (1995) within and between cultures and even over time.

The expanded dimensions of IND-COL could be useful to managers in an international setting where other scales provide only a bi-polar (i.e. individualism-collectivism) distinction. This distinction, in many cases, provides alternatives in considering an appropriate course of action. For example, a manager in a culture that is identified as collectivist may assume that praising individuals in front of the group may not be very welcomed by the worker. However, a vertical collectivist may not be averse to receiving praise in public. With the increasing diversity of the workforce in multinational companies, the expanded view of individualism-collectivism offers more options than the bipolar theory of cultural dimensions would. It is common practice, for example, to prepare management development programs to a predetermined style preference suited for individualist or collectivist setting. The expanded dimensionality offers a more refined position in these cases. Besides the quadra-dimensionality suggested by Singelis et al. (1995), there might be many different types of IND-COL (Gannon and Pillai, 2016) that could make the job of international managers more difficult. At least a suggestion that offers a quadra-dimensionality of these constructs provide more options to managers.

Our study dealt with the validity of the scale. However, we acknowledge other aspects and variations in different cultural settings. To be useful for research and practice, we should test the distinction between horizontal and vertical dimensions of IND-COL in many more countries. Initially, this distinction was tested in the United States, and without extensive validation in nonUS environments, it was applied in other countries to examine the relationship between different concepts. While our analysis of data from nine countries supports the instrument, it is not enough. Additional testing in other countries should follow. Results from different studies that had difficulty supporting the quadra-dimensionality of the instrument in other countries may be a confirmation of our suggestion. Combined with the evidence from the previous studies and the present one adds up to only 15 . Fifteen research findings is a small number as compared with the studies by Hofstede (1980), and the GLOBE project (House et al., 1999), whose models were tested in a large number of countries.

While this study dealt with and confirmed the expanded dimensions of IND-COL as proposed by Singelis et al. (1995), it is fitting to provide additional related suggestions. We acknowledge that the dominant form of cross-cultural research is based on the application of cultural dimensions. However, many researchers have called for or applied alternative modes of inquiry (e.g. Brannen and Salk, 2000; Fang, 2005/2006; Gannon, 2004, 2008, 2009, 2011, 2012; Gannon and Deb, 2018; Gannon and Pillai, 2016; Leung et al., 2005; Maruyama, 1980, 1992a, 1992b, 1994, 1995, 1999, 2004; Sackmann and Phillips, 2004). As Fang (2005/2006: 71) asserted, it is time for "[ ... ] shifting our mindset from the Cold War 'onion' way of analyzing culture to a new 'ocean' of understanding culture [...] in the age of globalization." Given the reality of globalization and the influence of convergence forces (Fatehi and Taasoobshirazi, 2020), we are encountering cultural parxodex that frustrates practitioners and scholars alike.

Singelis et al. (1995) gave us a method for expanding our framework of cultural analysis from individualism-collectivism to four constructs of VI, HI, VC, HC, and the present study indicated its value. However, we should go one step further using a more content-rich approach of cultural 
metaphoric and paradoxes. In doing so, we can look at national cultures two at a time, or look at major subgroups of a culture two at a time, such as Hispanic Americans and White Americans, as Gannon et al. (2005/2006) did. With this approach, we similarly integrate etic and emic strategies. The point is that regardless of the value and popularity of the dimensional method of cultural analysis, this approach is not rich enough. It assumes a bipolar position. Even the expanded quadradimensionality of Singelis et al. (1995) that we verified in the present study does not have the explanatory power of the qualitative methods of metaphors and paradoxes. Therefore, we should not exclude these techniques of cultural analysis that can enrich our discussion of cultural differences.

\section{Acknowledgements}

A research leave by Kennesaw State University provided support for this study. The authors gratefully acknowledge the assistance of the following professors and executives in data collection: S Al Ganideh, Al Zaytoonah University, Aman, Jordan; Sayeeda Bano, The University of Waikato, Hamilton, New Zealand; F Dasty, University of Mons, Belgium; M Duhaneanu, Institute for International Business, Bucharest, Romania; Bill Murphy, Heidelberg, USA, Kennesaw, GA, USA; KD Parhizgar, Texas A\&M International University, USA; ES Perez Wicht Meza, Catholic University, Arequipa, Peru; J Sanchez, University of Guadalajara, Mexico; M Taghavi and B Kazemi, Azad University; A Zaeri, Emtedad Consulting Company; M Asadi, Tehran, Iran; U Tate, Marshall University, Huntington, WV, USA; B Tatibekov, Demir Soleiman University, Almaty, Kazakhstan; Phan T Hong Xuan, Social Sciences and Humanities University of Hochiminh City, Vietnam National University, Hochiminh, Vietnam; Akio Yamamoto, Meiji University, Tokyo, Japan; CD Yong, Soongsil University, Seoul, South Korea.

\section{Declaration of conflicting interests}

The author(s) declared no potential conflicts of interest with respect to the research, authorship, and/or publication of this article.

\section{Funding}

The author(s) received no financial support for the research, authorship, and/or publication of this article.

\section{ORCID iD}

Kamal Fatehi (D) https://orcid.org/0000-0002-5159-9581

\section{References}

Abraham R (1997) The relationship of vertical and horizontal individualism and collectivism to intrapreneurship and organizational commitment. Leadership \& Organization Development Journal 18(4): 179-86.

Au KY (1999) Intra-cultural variation: evidence and implications for international business. Journal of International Business Studies 30(4): 700-812.

$\mathrm{Au}$ KY (2000) Intra-cultural variation as another construct of international management: a study based on secondary data of 42 countries. Journal of International Management 6: 217-38.

$\mathrm{Au}$ KY and Cheung MWL (2004) Intra-cultural variation and job autonomy in 42 countries. Organization Studies 25(8): 1339-62.

Bobbio A and Sarrica M (2009) Horizontal and vertical individualism and collectivism: an Italian adaptation of Singelis et al.'s scale and its relations with conflict management and leadership styles. Testing, Psychometric, Methodology in Applied Psychology (TPM) 16(4): 209-26.

Brannen MY and Salk J (2000) Partnering across borders. Human Relations 53(4): 451-87.

Brewer P and Venaik S (2012) On the misuse of national culture dimensions. International Marketing Review 29(6): 673-83. 
Carnevale PJ and Leung K (2001) Cultural dimensions of negotiation. In: Hogg MA and Tindale RS (eds), Blackwell Handbook of Social Psychology: Group Processes. John Wiley \& Sons, pp. 482-96.

Chiou JS (2001) Horizontal and vertical individualism and collectivism among college students in the United States, Taiwan, and Argentina. The Journal of Social Psychology 141(5): 667-78.

Chirkov VI, Lynch M, and Niwa S (2005) Application of the scenario questionnaire of horizontal and vertical individualism and collectivism to the assessment of cultural distance and cultural fit. International Journal of Intercultural Relations 29(4): 469-90.

Cukur CS, De Guzman MRT, and Carlo G (2004) Religiosity, values, and horizontal and vertical individualism-collectivism: a study of Turkey, the United States, and the Philippines. The Journal of Social Psychology 144(6): 613-34.

Dockens WS (2009) Mindscapes, ontology and global culture transition: morphogenesis as the pattern that connects. Journal of Organisation Transformation \& Social Change 6(3): 243-64.

Douglas M (1970) Natural Symbols: Explorations in Cosmology. London: Berrie and Rockliff.

Douglas M (1982) Essays in the Sociology of Perception. Berkely: University of California Press.

Fang T (2005/2006) From "onion" to "ocean": paradox and change in national cultures. International Studies of Management \& Organization 35(4): 71-90.

Fatehi K, Kedia BL, and Priestley JL (2015) Mindscapes and individual heterogeneity within and between cultures. Journal of Business Research 68(2): 291-98.

Fatehi K and Priestley JL (2018) Beauty is in the eye of beholder: intra-cultural and transcultural heterogeneity of individuals. Cross-Cultural Research 52(5): 443-67.

Fatehi K, Priestley JL, and Taasoobshiraiz G (2018) International marketing and intra-cultural heterogeneity. Asian Pacific Journal of Marketing and Logistics 30(3): 669-88.

Fatehi K and Taasoobshirazi G (2020) Contemplating the future: Mutating capitalism. Thunderbird Interantional Business Review, 62: 161-69

Fiske AP (1992) The four elementary forms of sociality: framework for a unified theory of social relations. Psychological Review 99(4): 689.

Gammack J (2002) Mindscape and internet-mediated communication. Journal of Computer-Mediated Communication 7(3): 1-19.

Gannon MJ (2004) Understanding Global Cultures: A Metaphorical Journey Through 28 Nations, Clusters of Nations, and Continents. Thousand Oaks: SAGE.

Gannon MJ (2008) Paradox of Cultures and Globalization. Thousand Oaks: SAGE.

Gannon MJ (2009) The cultural metaphoric method. International Journal of Cross Cultural Management 9(3): $275-87$.

Gannon MJ (2011) Cultural metaphors: their use in management practice as a method for understanding cultures. Online Readings in Psychology and Culture 7(1): 1-13.

Gannon MJ (2012) Sequential cross-cultural learning: from dimensions to cultural metaphors to paradoxes. Industrial and Organizational Psychology 5: 233-37.

Gannon M and Audia P (2000) The cultural metaphor: a grounded method for analyzing national cultures. In: Earley $\mathrm{P}$ and Singh H (eds), Innovations in International and Cross-Cultural Management. Thousand Oaks: SAGE, pp. 91-106.

Gannon MJ and Deb P (2018) Cross-cultural dimensions, metaphors, and paradoxes: an exploratory comparative analysis. In: Colette F (ed), Advances in Culturally-Aware Intelligent Systems and in CrossCultural Psychological Studies. Switzerland: International Springer Publishing.

Gannon E, Gupta A, Audia P, et al. (2005/2006) Cultural metaphors as frames of reference for nations: a sixnation study. International Studies of Management and Organization 35(4): 4-7.

Gannon MJ and Pillai R (2009) Understanding Global Cultures: Metaphorical Journey Through 29 Nations, Cluster of Nations, Continents, and Diversity. Thousand Oaks: SAGE.

Gannon MJ and Pillai R (2016) Understanding Global Cultures: Metaphorical Journey Through 34 Nations, Clusters of Nations, Continents, and Diversity. Thousand Oaks: SAGE. 
Gouveia VV, Clemente M, and Espinosa P (2003) The horizontal and vertical attributes of individualism and collectivism in a Spanish population. The Journal of Social Psychology 143(1): 43-63.

Green EG, Deschamps JC, and Paez D (2005) Variation of individualism and collectivism within and between 20 countries a typological analysis. Journal of Cross-Cultural Psychology 36(3): 321-39.

Guo X, Schwartz S, and McCabe M (2008) Aging, gender, and self: dimensionality and measurement invariance analysis on self-construal. Self and Identity 7: 1-24.

Gurven M, Zanolini A, and Schniter E (2008)Culture sometimes matters: intra-cultural variation in pro-social behavior among Tsimane Amerindians. Journal of Economic Behavior \& Organization 62: 587-607.

Györkös C, Becker J, Massoudi K, et al. (2012) Comparing the horizontal and vertical individualism and collectivism scale and the Auckland individualism and collectivism scale in two cultures: Switzerland and South Africa. Cross-Cultural Research 47(3): 310-31.

Hatt K (2009) Considering complexity: toward a strategy for non-linear analysis. Canadian Journal of Sociology 34(2): 313-47.

Hentschel U and Sumbadze N (2002) Individual differences in mindscapes and attitudes: an exploratory crosscultural study. Social Behavior and Personality 30(3): 213-22.

Hofstede G (1980) Culture's Consequences: International Differences in Work-Related Values. Beverly Hills: SAGE.

Hofstede G (2001) Culture's Consequences, 2nd ed. Thousand Oak: SAGE.

Hofstede G and Bond MH (1988) The Confucius connection: from cultural roots to economic growth. Organizational Dynamics 16(4): 5-21.

Hornik S and Tupchiy A (2006) Culture's impact on technology mediated learning: the role of horizontal and vertical individualism and collectivism. Global Information Management 14(4): 31-6.

House RJ, Hanges PJ, Javidan M, et al. (2004) Culture, Leadership, and Organizations: The GLOBE Study of 62 Societies. Thousand Oaks: SAGE.

House RJ, Hanges PJ, Ruiz-Quintanilla SA, et al. (1999) Cultural influences on leadership and organizations: Project GLOBE. Advances in Global Leadership 1(2): 171-233.

Inkeles A and Levinson DJ (1969) National character: the study of modal personality and sociocultural systems. In: Lindzey G and Aronson E (eds), The Handbook of Social Psychology, vol. 4, pp. 418-506 (First published in 1954).

Kim MS, Sharkey WF, and Singelis TM (1995) The relationship between individuals' self-construals and perceived importance of interactive constraints. International Journal of Intercultural Relations 18(1): $117-40$.

Kirkman BL, Lowe KB, and Gibson CB (2006) A quarter-century of cultures' consequences: a review of empirical research incorporating Hofstede's cultural values framework. Journal of International Business Studies 37(3): 285-320.

Kluckhohn FR and Strodtbeck FL (1961) Variations in Value Orientations. Oxford: Row, Peterson.

Komarraju M and Cokley KO (2008) Horizontal and vertical dimensions of individualism-collectivism: a comparison of African Americans and European Americans. Cultural Diversity and Ethnic Minority Psychology 14(4): 336.

Komarraju M, Dollinger SJ, and Lovell JL (2008) Individualism-collectivism in horizontal and vertical directions as predictors of conflict management styles. International Journal of Conflict Management 19 (1): $20-35$.

Kuhn MH and McPartland TS (1954) An empirical investigation of self-attitudes. American Sociological Review 19(1): 68-76.

Kurman J and Sriram N (2002) Interrelationships among vertical and horizontal collectivism, modesty, and self-enhancement. Journal of Cross-Cultural Psychology 33(1): 71-86.

Le TN (2005) Narcissism and immature love as mediators of vertical individualism and ludic style. Journal of Social and Personal Relationships 22(4): 543-60. 
Lee W-N and Choi SM (2005)The role of horizontal and vertical individualism and collectivism in online consumer's response toward persuasive communication on the Web. Journal of Computer-Mediated Communication 11(1): 317-36.

Leung K, Bhagat RS, Buchan NR, et al. (2005) Culture and international business: recent advances and their implications for future research. Journal of Intercultural Business Studies 36 (4): 357-78.

Levine TR, Park HS, and Kim RK (2007) Some conceptual and theoretical challenges for cross-cultural communication research in the 21st century. Journal of Intercultural Communication Research 36(3): 205-21.

Markus HR and Kitayama S (1991) Culture and the self: implications for cognition, emotion, and motivation. Psychological Review 98(2): 224.

Markus HR and Kitayama S (2003) Culture, self, and the reality of the social. Psychological Inquiry 14(3-4): 277-83.

Maruyama M (1980) Mindscape and science theories. Current Anthropology 21(5): 589-608.

Maruyama M (1992a) Anti-monopoly law to prevent dominance by one theory in academic departments. Human Systems Management 11: 219-20.

Maruyama M (1992b) Changing dimensions in international business. Academy of Management Executive 6 (3): 88-96.

Maruyama M (1994) Psychological tests for epistemological heterogeneity across cultures. Communication and Cognition 27(4): 277-396.

Maruyama M (1995) Individual epistemological heterogeneity across cultures and its use in organizations. Cybernetica 37(3): 215-49.

Maruyama M (1999) Heterogram analysis: where the assumption of normal distribution is illogical. Human Systems Management 18: 53-60.

Maruyama M (2004) Polyocular vision or sub-understanding? Organization Studies 25(3): 467-80.

McSweeney B (2002a) Hofstede's model of national cultural differences and their consequences: a triumph of faith-a failure of analysis. Human Relations 55(1): 89-118.

McSweeney B (2002b) The essentials of scholarship: a reply to Geert Hofstede. Human Relations 55(11): $1363-72$.

McSweeney B (2013) Fashion founded on a flaw: the ecological mono-deterministic fallacy of Hofstede, GLOBE, and followers. International Marketing Review 30(5): 483-504.

Minkov M and Hofstede G (2011) The evolution of Hofstede's doctrine. Cross Cultural Management: An International Journal 18(1): 10-20.

Montague S and Morais R (1975) Football games and rock concerts: the ritual enactment of American success models. In: Arens W (ed), The American Dimensions: Cultural Myths and Realities. Los Angeles: Alfred Publishing, pp. 32-55.

Nielsen C and Mariotto J (2005/2006) The tango metaphor: the essence of Argentina's national identity. International Studies of Management \& Organization, Winter 35(4): 8-36.

Nelson MR and Shavitt S (2002) Horizontal and vertical individualism and achievement values a multimethod examination of Denmark and the United States. Journal of Cross-Cultural Psychology 33(5): 439-58.

Noordin F, Williams T, and Zimmer C (2002) Career commitment in collectivist and individualist cultures: a comparative study. International Journal of Human Resource Management 13(1): 35-54.

Osland JS and Bird A (2000) Beyond sophisticated stereotyping: cultural sensemaking in context. The Academy of Management Executive 14(1): 65-79.

Oyserman D (1993) The lens of personhood: viewing the self and others in a multicultural society. Journal of Personality and Social Psychology 65(5): 993.

Oyserman D, Coon HM, and Kemmelmeier M (2002) Rethinking individualism and collectivism: evaluation of theoretical assumptions and meta-analyses. Psychological Bulletin 128(1): 3.

Parsons T and Shills E (1951) Toward a Theory of Social Action: Theoretical Foundation for the Social Sciences. New York: Haroer Torchbook. 
Probst TM, Carnevale P, and Triandis HC (1999) Cultural values in intergroup and single-group social dilemmas. Organizational Behavior and Human Decision Process 77(3): 171-91.

Sakmann SA and Phillips ME (2004) One's many cultures: a multiple cultures perspective. In: Boyacigiller NA, Goodman RA, and Phillips ME (eds), Crossing Cultures: Insights from Master Teachers. New York: Routledge.

Singelis TM (1994) The measurement of independent and interdependent self-construals. Personality and Social Psychology Bulletin 20(5): 580-91.

Singelis TM, Triandis HC, Bhawuk DP, et al. (1995) Horizontal and vertical dimensions of individualism and collectivism: a theoretical and measurement refinement. Cross-Cultural Research 29(3): 240-75.

Sivadas E, Bruvold NT, and Nelson MR (2008) A reduced version of the horizontal and vertical individualism and collectivism scale: a four-country assessment. Journal of Business Research 61(3): 201-10.

Sivakumar K and Nakata C (2001) The stampede toward Hofstede's framework: avoiding the sample design pit in cross-cultural research. Journal of International Business Studies 32(3): 555-74.

Smith P and Schwartz S (1977) Values. In: Berry J, Segall M, and Kagitcibasi C (eds), Handbook of CrossCultural Psychology, 2nd ed, vol. 3, pp. 77-118.

Soh S and Leong FT (2002) Validity of vertical and horizontal individualism and collectivism in Singapore relationships with values and interests. Journal of Cross-Cultural Psychology 33(1): 3-15.

Taras V, Rowney J, and Steel P (2009) Half a century of measuring culture: Review of approaches based on analysis of 121 instruments for quantifying culture. Journal of International Management 15(4): 357-73.

Taras V, Sarala R, Muchinsky P, et al. (2013) Opposite ends of the same stick? Multi-method test of the dimensionality of individualism and collectivism. Journal of Cross-Cultural Psychology 45(2): 213-45.

Thompson M and Wildavsky A (1986) A cultural theory of information bias in organizations. Journal of Management Studies 23(3): 273-86.

Triandis HC (1993) Collectivism and individualism as cultural syndromes. Cross-Cultural Research 27(3-4): $155-180$.

Triandis HC (1995) Individualism \& Collectivism. Boulder: Westview Press.

Triandis HC and Gelfand MJ (1998) Converging measurement of horizontal and vertical individualism and collectivism. Journal of Personality and Social Psychology 74(1): 118-28.

Trompenaars F and Hampden-Turner C (1998) Riding the Waves of Culture. New York: McGraw-Hill.

Tung R (2008) The cross-cultural research imperative: the need to balance cross-national and intra-national diversity. Journal of International Business Studies 39(1): 41-6.

Tusi AS, Nifadkar SS, and Ou AY (2007) Cross-national, cross-cultural organizational behavior research: advances, gaps, and recommendations. Journal of Management 33: 426-78.

Vargas JH and Kemmelmeier M (2013) Ethnicity and contemporary American culture a meta-analytic investigation of horizontal-vertical individualism-collectivism. Journal of Cross-Cultural Psychology 44(2): 195-222.

Venaik S and Midgley DF (2015) Mindscapes across landscapes: archetypes of transnational and subnational culture. Journal of International Business Studies 46(9): 1051-79.

Voronov M and Singer JA (2002) The myth of individualism-collectivism: a critical review. The Journal of Social Psychology 142(4): 461-80.

Yolles M and Fink G (2009) Migrating personality theories, Part 2: toward a theory of the balanced personality. Kebernetes 38(9): 1461-90. 


\section{Appendix I}

\section{The Abridged Scale Version of Singelis et al. (1995).}

Survey. Please, complete a 16-item questionnaire. Your participation is voluntary.

It takes no more than a few minutes of your time. No personal information is collected. You will remain anonymous. Your response, along with responses from others will be analyzed as a group. All information is treated confidentially. The research has no known risks,

Thank you.

Date:

Age: Years: $17-24 \longrightarrow$. 25-29-30-34 Over $35-$.

Gender: Male —, Female -

In the following, please, place on the front of each item a number from 1 to $9(1,2,3,4,5,6,7,8,9)$. With 1 indicating disagreement, minimum, very seldom, not at all, and 9 indicating complete agreement, maximum, always.

1. I'd rather depend on myself than others.

2. If a coworker gets a prize, I would feel proud.

3. It is important that I do my job better than others.

4. Parents and children must stay together as much as possible.

5. I rely on myself most of the time; I rarely rely on others.

6. The well-being of my coworkers is important to me.

7. Winning is everything.

8. It is my duty to take care of my family even when I have to sacrifice what I want.

9. My personality independent of others is very important to me.

10. To me, pleasure is spending time with others.

11. Competition is the law of nature.

12. Family members should stick together no matter what sacrifices are required.

13. I prefer to be direct and forthright when discussing with people.

14. I feel good when I cooperate with others.

15. When another person does better than I do, I get tense.

16. It is important to me that I respect the decisions made by my groups.

Note: These are the same items that were loaded on the four dimensions as reported by Traindis and Gelfand (1998) on Table 2 of their study. However, we replaced item number 3 of that table (I often do "my own thing") with item \#13 on this scale (I prefer to be direct and forthright ... ). We thought that people of other cultures might not fully comprehend item \#3. The selection of this item (\#13) was aided by the fact that it was an item on the original 32 items of Singelis et at. (1995) scale, it had a high factor loading, and was in the same category. 